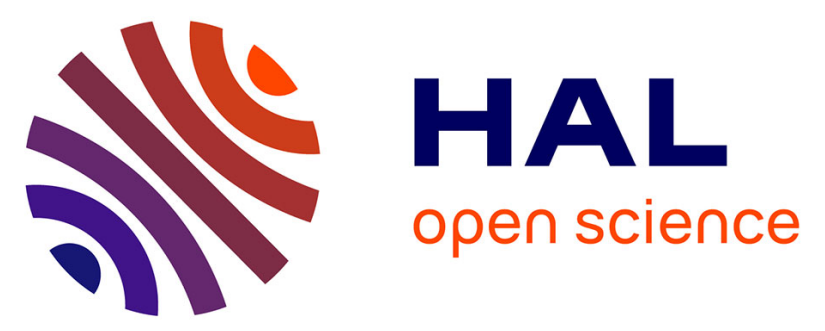

\title{
Quality of life and female sexual function after skinning vulvectomy with split-thickness skin graft in women with vulvar intraepithelial neoplasia or vulvar Paget disease.
}

Vincent Lavoué, A. Lemarrec, N. Bertheuil, Sébastien Henno, Habiba

Mesbah, Eric Watier, Jean Levêque, Karine Morcel

\section{To cite this version:}

Vincent Lavoué, A. Lemarrec, N. Bertheuil, Sébastien Henno, Habiba Mesbah, et al.. Quality of life and female sexual function after skinning vulvectomy with split-thickness skin graft in women with vulvar intraepithelial neoplasia or vulvar Paget disease.. EJSO - European Journal of Surgical Oncology, 2013, 39 (12), pp.1444-50. 10.1016/j.ejso.2013.09.014 . inserm-00871204

\section{HAL Id: inserm-00871204 https://www.hal.inserm.fr/inserm-00871204}

Submitted on 9 Oct 2013

HAL is a multi-disciplinary open access archive for the deposit and dissemination of scientific research documents, whether they are published or not. The documents may come from teaching and research institutions in France or abroad, or from public or private research centers.
L'archive ouverte pluridisciplinaire HAL, est destinée au dépôt et à la diffusion de documents scientifiques de niveau recherche, publiés ou non, émanant des établissements d'enseignement et de recherche français ou étrangers, des laboratoires publics ou privés. 
Quality of life and female sexual function after skinning vulvectomy with split-thickness skin graft in women with vulvar intraepithelial neoplasia or vulvar Paget disease.

V. Lavoué ${ }^{1,2+*}$, A. Lemarrec ${ }^{1+}$, N. Bertheuil ${ }^{3}$, S. Henno ${ }^{4}$, H. Mesbah ${ }^{2}$, E. Watier ${ }^{3}$, J. Levêque ${ }^{1,2}, \mathrm{~K}$. Morcel $^{1}$

${ }^{1}$ Department of Gynecology, Rennes University Hospital, 16 rue de Bulgarie, B.P. 90347, F35203 Rennes Cedex 2, France

${ }^{2}$ Department of Surgery, Eugène Marquis Comprehensive Cancer Center, Av Bataille Flandres-Dunkerque C.S.44229, F-35042 Rennes Cedex, France

${ }^{3}$ Department of Plastic and Reconstructive Surgery, Rennes University Hospital, 16 rue de Bulgarie, B.P. 90347, F-35203 Rennes Cedex 2, France

${ }^{4}$ Department of Pathology, Rennes University Hospital, 2 rue H Le Guilloux, 35000 Rennes cedex 09, France

${ }^{+}$V.L. and A.L. both contributed equally to this work.

*Correspondence: Vincent Lavoué, Service de Gynécologie, CHU de Rennes, 16 rue de Bulgarie, B.P. 90347, F-35203 Rennes Cedex 2, France - Email: vincent.lavoue@,chu$\underline{\text { rennes.fr }}$

\section{CONFLICT OF INTEREST:}

No conflict of interest exists for any of the authors. 


\section{Abstract}

Objective: Vulvar intraepithelial neoplasia (VIN) and vulvar Paget disease are managed with either vulvectomy, destructive treatments (laser, antimitotic drugs) or immunostimulants. All these options are associated with functional complications. The purpose of this study was to evaluate the surgical technique consisting of skinning vulvectomy with split-thickness skin graft, and its effect on overall quality of life and sexual function.

Methods: a retrospective study was conducted on thirteen patients who underwent skinning vulvectomy with split-thickness skin graft between 1999 and 2009. Overall quality of life and sexual function were assessed with the Medical Outcome Study Short Form 36 (MOS SF-36) and Female Sexual Function Index (FSFI), respectively.

Results: The median age of patients was 54 (range: 33-77) years. Three patients had Paget disease and 10 patients had VIN lesions. The excision margins were clear in $46 \%$ of cases. The incidence of occult cancer was $31 \%$. The mean follow-up period was $77( \pm 35)$ months. Four patients experienced a relapse of their intraepithelial disease. The mean disease-free survival was $58( \pm 44)$ months. There was no significant difference in MOS SF-36 scores between the study population and the general population. The patients assessed with the FSFI regained normal sexual function after the surgical procedure.

Conclusion: Skinning vulvectomy with split-thickness skin graft is a feasible technique yielding good results in terms of quality of life and sexual function. It enables occult cancer to be diagnosed in patients with VIN or Paget disease. 
Keywords: Vulvectomy; Skin graft; Vulvar intraepithelial neoplasia; Vulvar Paget disease; Quality of life 


\section{Introduction}

Vulvar intraepithelial neoplasia (VIN) causes pain and itching and can have major psychological and sexual repercussions. Incidence is low (5 new cases for 100,000 women worldwide $^{1}$ ) but has risen in developed countries (rise of $411 \%$ from 1973 to 2000), mainly affecting young women ${ }^{2}$. The International Society for the Study of Vulvar Disease (ISSVD) divides VIN into usual-type VIN and differentiated-type VIN ${ }^{3}$. Usual-type VIN affects women between the age of 30 and 50 and is strongly associated with high-risk HPV ${ }^{4}$. Differentiated-type VIN affects older women often presenting lichen sclerosus. There is also vulvar Paget disease, which is an adenocarcinoma with intraepithelial development in the malpighian layer ${ }^{5}$. VIN and Paget disease are intraepithelial lesions and can be associated with invasive lesions ${ }^{6-8}$. Management of these lesions involves monitoring symptoms, preventing invasion and preserving normal vulvar anatomy and function. Radical local excision is the standard treatment as it enables histological analysis with detection of potential invasion but it often compromises vulvar anatomy with major repercussions on quality of life and sexual function ${ }^{9}{ }^{10}$. Destructive treatments (such as laser vaporization) ${ }^{11}$ or immunostimulants (such as imiquimod) ${ }^{12} 13$ have disadvantages, including local side effects and a lack of histological analysis of the full lesions.

Split-thickness skin graft is a common reparative surgical technique ${ }^{14}$. For patients with VIN or vulvar Paget disease, the skinning vulvectomy with a split-thickness skin graft appears to offer an interesting option for preventing the psychosexual disorders related to mutilating vulvar surgery. This surgical approach was described for the first time in $1968{ }^{15}$ then resumed in $1986^{16}$. The technique has been little used and never been assessed at the functional level.

The purpose of this study was to evaluate the surgical technique consisting of split-thickness skin graft after skinning vulvectomy, along with its impact on the overall quality of life and 
sexual function of patients, as assessed with the Medical Outcome Study Short Form 36 (MOS SF-36) questionnaire ${ }^{17}$ and the Female Sexual Function Index (FSFI) ${ }^{18}$. 


\section{Materials and methods}

\section{Patients}

We conducted a retrospective cohort study on patients who underwent skinning vulvectomy with split-thickness skin graft. From the Department of Gynecology database we identified the cases of 13 women requesting skinning vulvectomy with split-thickness skin graft at Rennes Teaching Hospital between 1999 and 2009 from a total number of 226 vulvectomies (total, partial or skinning). The study was approved by the Institutional review board of the French college of obstetricians and gynecologists (CEROG-2010-26-R1) and informed consent was given by all the patients included.

The outcome measures were the rate of cancer found at final pathological analysis of vulvectomy, quality of life and sexual function of patients.

The medical records and outpatient records were reviewed.

\section{Surgical procedure}

After a preoperative diagnosis based on biopsy findings, the patients were operated on under general or regional anesthesia in the lithotomy position. The procedure was performed by a two-surgeon team including a gynecology surgeon and a plastic surgeon. It involved excision of the epidermis and the dermis extending beyond the lesions ( $\geq 5 \mathrm{~mm}$ ) and preserving the subcutaneous tissue. The split-thickness skin graft was taken from the inner aspect of the thigh with a Braun air dermatome or a Dufourmentel surgical razor (0.012 in. thick). The graft was applied to the wound following vulvectomy. The surrounding edges were sutured with 4/0 Vicryl absorbable sutures, achieving a tension-free closure. A bolster dressing was applied for 3 to 4 days to optimize adherence (Figure 1). We assessed postoperative pain according to both a visual analog scale (VAS) rated from 0 to 10 and postoperative analgesic requirements. Pathological analysis 
Preoperative biopsy specimens were fixed in $10 \%$ formaldehyde and embedded in paraffin. Each biopsy was examined using multiple semi-serial sections. According to the established criteria (ISSVD) ${ }^{3}$, we included cases of usual-type and differentiated-type VIN and Paget disease. The surgical resection specimens were oriented by the surgeon and sent fresh directly to the Pathology Department. They were pinned to a rigid board and fixed in $10 \%$ formaldehyde for 24 hours. All surgical margins were marked with India ink. The samples taken concerned the excision margins examined in full, the entire operative specimen examined in stages and the entire macroscopic lesion. The slides were reviewed by two pathologists (S.H. and Florence Burtin, MD).

\section{Functional assessment}

In December 2009, the patients were contacted for the study. They completed two validated instruments: the FSFI and a French validated translation of the MOS SF-36 ${ }^{17}$. The MOS SF36 is preferred for quality of life assessment instead of QLQC-30 (from European Organization for Research and Treatment of Cancer) or DLQI (Dermatology Life Quality Index) because of VIN or vulvar Paget disease are precancerous diseases (not cancer) and because of DLQI is a well known questionnaire for dermatologists but less known for others practitioners. For quality of life evaluation, the SF-36 questionnaire evaluates physical functioning, bodily pain, general health, vitality, social functioning, mental health, health transition and role-physical and role-emotional domains if patients have any problems with their work or other regular daily activities as a result of their physical health or any emotional problems, respectively. Each of the 36 items is scored on a 0-100 range, so that a high score defines a more favorable health state. All recorded items are averaged together to form the different scales for each of the eight mentioned specific domain. The scores obtained in studied population with the MOS SF-36 were compared with those of the reference French general female population ${ }^{17} 19$. 
FSFI is a well-validated, short and understandable instrument used to assess healthy women and women who have experienced vulvar excision ${ }^{20}$. The FSFI measures five domains: desire, arousal, lubrication, orgasm, and pain on a scale of 2.0 to 36.0. A score strictly higher than 26 indicates normal sexual activity and a score of 26 or lower indicates sexual dysfunction $^{21}$.

The both questionnaires provide exclusively self-report measures and do not include objective assessments by medical staff.

\section{Statistical analysis}

We used SAS (Statistical Analysis System) version 9.2 software. Continuous variables were compared with Student's $t$-test and categorical variables were compared with the Chi 2 test or Fisher's exact test, as appropriate. We used Student's $t$-test which compares the mean value observed with a known mean of the reference population for the MOS SF-36 ${ }^{22}$. P values $<0.05$ were considered statistically significant. Progression-free survival was analyzed using the Kaplan-Meier method. 


\section{Results}

Epidemiological and clinical characteristics of the study population

During the study period, 13 women referred for VIN or Paget disease underwent skinning vulvectomy with split-thickness skin graft. The median age of patients was 54 (range: 33-77) years. Body mass index median was 23 (range: 20-36) $\mathrm{kg} / \mathrm{m}^{2}$. Among the patients, 4 had a history of cervical disease, and 5 had a history of vulvovaginal disease, two of whom had undergone vulvar surgery. Six patients were smokers. Indications for performing skinning vulvectomy were usual-type VIN in 9 cases, differentiated-type VIN in one case and vulvar Paget disease in 3 cases determined from the preoperative biopsy (Table 1) ${ }^{3}$. The patients' symptoms were intense pruritus in $75 \%$ of cases, pain in $37 \%$ of cases and burning sensations in $12 \%$ of cases. Vulvar lesions measured 39 (range: 9-90) $\mathrm{mm}$ in diameter at their widest point and 22 (range: 10-40) $\mathrm{mm}$ in diameter at their narrowest point. The lesions were multifocal in 11 out of 13 cases and bilateral in 5 out of 13 cases.

Surgical procedure and pathology data

Median operating time was 80 (range: 60-120) minutes. Resection diameter was 65 (range: 35-180) $\mathrm{mm}$ at its widest point and 60 (range: $23-130$ ) $\mathrm{mm}$ at its narrowest point. The median hospital stay was 14 (range: 7-25) days. The maximum median pain assessed by the VAS was 2 (range: $0-5$ ) mm, 2 (range: $0-8$ ) mm, 0 (range: $0-4$ ) $\mathrm{mm}$ and 0 (range: $0-0$ ) on the 1st, 2nd, 5th and 10th day post-surgery, respectively. All patients received analgesics in the postoperative period: $46 \%, 61 \%, 54 \%$ and $13 \%$ of patients needed morphine on the 1 st, $2 \mathrm{nd}$, 5th and 10th day post-surgery, respectively.

The final histological examination of the operative specimen confirmed the preoperative diagnosis in all cases. The cases of usual-type VIN were multicentric in 7 cases out of 13 patients. The margins were clear in 6 cases: 5 cases of VIN and 1 case of Paget disease. The lesion diameters measured 38 (range: 9-40) $\mathrm{mm}$ at their widest point for the patients with a 
clear resection margin vs. 38 (range: 13-90) $\mathrm{mm}$ for the patients with an unclear resection margin $(\mathrm{p}=0.12)$. In 4 cases associated cancer was found: two cases were associated with usual-type VIN (invasive epidermoid carcinoma measuring $4.0 \mathrm{~mm}$ for one case and $2.8 \mathrm{~mm}$ for the other case) and two cases were associated with Paget disease (one case with 2 microinvasive adenocarcinomatous foci and one case with an $8 \mathrm{~mm}$ invasive adenocarcinoma). Macroscopic margins were $>1 \mathrm{~cm}$. The intraepithelial lesion diameters measured 39 (range: 10-45) $\mathrm{mm}$ at their widest point for the patients with no associated cancer vs. 38 (range: 9-90) $\mathrm{mm}$ for the patients with associated cancer $(\mathrm{p}=0.68)$. For three of the patients with associated cancer adjuvant radiotherapy treatment was administered concomitantly, because of microscopic margin involvement. The fourth patient with associated cancer became pregnant in the postoperative follow-up period and gave birth to a live healthy child. She subsequently underwent unilateral inguinal curettage (no metastatic lymph node invasion) and did not receive radiotherapy.

\section{Follow-up and determinants of recurrence}

The mean follow-up period was $77( \pm 35)$ months. Mean disease-free survival for the population was $58( \pm 44)$ months (Figure 2$)$. The disease-free survival rate was $73 \%$ at 2 years and $64 \%$ at 5 years. Four patients (31\%) relapsed during follow-up. The mean time to recurrence was $19( \pm 13)$ months. All cases of recurrence were marked by the re-emergence of vulvar symptoms such as pruritus, burning sensation or pain. One patient experienced a relapse of Paget disease 16 months after surgery. One patient experienced a relapse of usualtype VIN 10 months after surgery. Lastly, 2 patients relapsed with invasive disease 16 and 32 months from surgery, respectively.

Evaluation of quality of life and sexual function after skinning vulvectomy with split-thickness skin graft for vulvar intraepithelial neoplasia or vulvar Paget disease. 
Among the 13 patients, 11 patients responded to the MOS SF-36 questionnaire. Scores for the SF-36 questionnaire are shown in Table 2. No significant difference was found when comparing the population that underwent skinning vulvectomy with split-thickness skin graft with the overall female population ${ }^{19}$, regardless of the domain considered (Table 2).

Among the 13 patients, 10 patients responded to the FSFI questionnaire assessing sexual function. Among the patients, 7 had no sexual activity, and their median age was 70 (38-77) years. The 3 patients who stated having sexual activity had a median age of 34 (33-40) years. Two patients had normal sexual activity with final scores of 31 and 32.4 for the FSFI. For these patients, the time between surgery and response to the questionnaire was 94 and 100 months, and neither underwent radiotherapy or experienced relapse. The patient with sexual dysfunction (with a final FSFI score of 14.9) responded 61 months after surgery. She received radiotherapy following discovery of an invasive carcinoma post-surgery and subsequently had to undergo a left hemivulvectomy due to recurrence of the vulvar lesion. 


\section{Discussion}

Skinning vulvectomy with split-thickness skin graft in the case of VIN or vulvar Paget disease shows good results in terms of quality of life while allowing histological analysis of the entire lesions, thus enabling the screening of underlying invasive cancer. Although the study is not sufficient to answer the question about sexual disorders following a skinning vulvectomy, because of the sexual function could be assessed for only two patients, which presented normal sexual function.

\section{Occult cancers}

Our study has several limitations such as the retrospective character of the study with no functional assessment before the surgery, the small number of patients or some questionnaires administered many years after surgery. Nevertheless, our study provides interesting information about management of VIN or vulvar Paget disease. In our series, the skinning vulvectomy revealed 4 in 13 cases $(31 \%)$ of cancer on the final operative specimen. In the literature, occult cancers were found on final histological analysis of the vulvectomy resection specimens in 3 to $22 \%$ of cases for VIN ${ }^{11} 162324$ and in $16 \%$ to $30 \%$ of cases for vulvar Paget disease 2526 . In our study, the higher incidence of occult cancer is probably due to the presence of large multifocal intraepithelial lesions.

\section{Recurrence of intraepithelial vulvar disease}

Secondly, recurrence is significantly linked to the size and multifocal nature of the lesions and to positive margins 67112427 . The incidence of involved margins is $54 \%$ in our study, comparable with the published radical vulvectomy series which report involved margins of between $47 \%$ and $61 \%$ of VIN cases ${ }^{6724}$ and $54 \%$ of vulvar Paget disease cases 2628 . Regarding relapse of intraepithelial vulvar lesions, $31 \%$ of patients relapsed over a follow-up period of $77( \pm 35)$ months in our study, comparable with published surgical series which report a relapse rate of between $26 \%$ and $37 \%$ for VIN lesions ${ }^{624} 27$ and $47 \%$ for vulvar Paget 
lesions ${ }^{5}$. The depth of skinning vulvectomy resection estimated at $5 \mathrm{~mm}$ (compared with a 15 mm minimum thickness for a total vulvectomy) does not appear to negatively influence the risk of relapse which seems logical insofar as the lesions are strictly non-invasive.

\section{Quality of life and sexual function}

Data about quality of life and sexual function assessments after vulvar surgery are scarce in literature ${ }^{91029-31}$. Furthermore, the comparisons between published clinicopathological series are difficult because of the use of several tools for the assessment of quality of life: the European Organization for Research and Treatment of Cancer QLQ-C30 (QLQ C-30) scale was used by Likes and $\mathrm{col}^{10}$ or de Melo Ferraira and col ${ }^{30}$, or the MOS SF-36 by us or others 31. The sexual function assessments suffers the same difficulties: DSM IV criteria were used by Green and al ${ }^{9}$ and FSFI was used by us or others ${ }^{10}$. Furthermore, scores were not always well reported: Likes et col reported correlations with FSFI score and clinicopathological data but they did not report the FSFI score itself ${ }^{10}$. Nevertheless, the overall published data report that vulvectomy has a negative impact on sexual function and quality of life ${ }^{29}$. Conversely, the skinning vulvectomy with split-thickness skin graft did not show negative impact in present study, but more studies are necessary to confirm this low side effect rate.

\section{Comparison between surgery and medical treatment}

The alternative to surgical resection of VIN or vulvar Paget disease lesions is destruction by $\mathrm{CO} 2$ laser vaporization ${ }^{11}$, cryocoagulation ${ }^{32}$ or imiquimod ${ }^{7811}$. Therapeutic vaccines for HPV 16 are currently undergoing clinical trials and may not as yet be recommended ${ }^{33}$. The risk of relapse seems unrelated to treatment type for some authors ${ }^{8}$ or not significantly different between surgical resection (26\% of relapse) and imiquimod (14\%), which are themselves significantly superior to destruction by laser ( $45 \%$ of relapse), for others ${ }^{27}$. In a randomized trial of imiquimod vs. placebo, VIN lesions persisting after 1 year of treatment were observed in 15 out of 24 patients $(62 \%)^{12}$. Imiquimod is also recommended as treatment 
for vulvar Paget disease ${ }^{34-36}$. Imiquimod seems to offer advantages over surgical resection because of a risk of relapse that is potentially lower than surgery ${ }^{27}$, probably due to the eradication of HPV 16, the causal agent of usual-type VIN ${ }^{37}$. However, treatment by imiquimod has one major disadvantage in that it does not allow a full histological analysis of lesions (and hence invasive cancer may be overlooked), and has non-negligible side effects such as pain, itching and skin erosion ${ }^{12}$. These side effects are all the more severe since the lesions are extensive and require application over several weeks ${ }^{12}{ }^{13}$. In our series, skinning vulvectomy with split-thickness skin graft can alleviate pain in a few days with a VAS of 0 on the 10th day post-surgery, while maintaining good functionality in terms of sexuality and quality of life in the long term once healing has occurred.

\section{Surgical technical aspect}

Of note, one of the limits of skinning vulvectomy with split-thickness skin graft is linked to the seat of the lesions as shown in our study. Posterior and lateral lesions are the site of predilection, whereas skin grafts are less likely to take on anterior lesions and in particular lesions of the clitoris. 


\section{Conclusion:}

The ideal treatment for VIN or vulvar Paget disease should be acceptable to patients, alleviate symptoms, enable diagnosis of possible invasion, eliminate the risk of relapse by performing full resection of lesions and removing the causal agent, and preserve quality of life (body image and sexuality in particular). Skinning vulvectomy with split-thickness skin graft fulfills a certain number of these objectives (acceptability and postoperative comfort, full analysis of lesions, possibility of wide excision margins), in particular in posterolateral lesions. However, given the high relapse rate observed, adjuvant treatments warrant investigation, in particular etiological treatments such as therapeutic vaccination ${ }^{33}$ or immune response modulators that facilitate HPV clearance ${ }^{37}$ in extended and multifocal forms.

\section{CONFLICT OF INTEREST:}

No conflict of interest exists for any of the authors.

Acknowledgments: Acknowledgments are due to Tracey Westcott for her assistance in the preparation of the manuscript and to Florence Burtin for reviewing pathological slides. 


\section{References}

1. Joura EA, Losch A, Haider-Angeler MG, Breitenecker G, Leodolter S. Trends in vulvar neoplasia. Increasing incidence of vulvar intraepithelial neoplasia and squamous cell carcinoma of the vulva in young women. J Reprod Med 2000;45:613-5.

2. Judson PL, Habermann EB, Baxter NN, Durham SB, Virnig BA. Trends in the incidence of invasive and in situ vulvar carcinoma. Obstet Gynecol 2006;107:1018-22.

3. Sideri M, Jones RW, Wilkinson EJ, et al. Squamous vulvar intraepithelial neoplasia: 2004 modified terminology, ISSVD Vulvar Oncology Subcommittee. J Reprod Med 2005;50:807-10.

4. Goffin F, Mayrand MH, Gauthier P, et al. High-risk human papillomavirus infection of the genital tract of women with a previous history or current high-grade vulvar intraepithelial neoplasia. J Med Virol 2006;78:814-9.

5. Shaco-Levy R, Bean SM, Vollmer RT, et al. Paget disease of the vulva: a study of 56 cases. Eur J Obstet Gynecol Reprod Biol 2009.

6. Jones RW, Rowan DM, Stewart AW. Vulvar intraepithelial neoplasia: aspects of the natural history and outcome in 405 women. Obstet Gynecol 2005;106:1319-26.

7. van Seters $M$, van Beurden $M$, de Craen AJ. Is the assumed natural history of vulvar intraepithelial neoplasia III based on enough evidence? A systematic review of 3322 published patients. Gynecol Oncol 2005;97:645-51.

8. van de Nieuwenhof HP, van der Avoort IA, de Hullu JA. Review of squamous premalignant vulvar lesions. Crit Rev Oncol Hematol 2008;68:131-56.

9. Green MS, Naumann RW, Elliot M, Hall JB, Higgins RV, Grigsby JH. Sexual dysfunction following vulvectomy. Gynecol Oncol 2000;77:73-7.

10. Likes WM, Stegbauer C, Tillmanns T, Pruett J. Correlates of sexual function following vulvar excision. Gynecol Oncol 2007;105:600-3.

11. Hillemanns P, Wang X, Staehle S, Michels W, Dannecker C. Evaluation of different treatment modalities for vulvar intraepithelial neoplasia (VIN): $\mathrm{CO}(2)$ laser vaporization, photodynamic therapy, excision and vulvectomy. Gynecol Oncol 2006;100:271-5.

12. van Seters M, van Beurden M, ten Kate FJ, et al. Treatment of vulvar intraepithelial neoplasia with topical imiquimod. $N$ Engl J Med 2008;358:1465-73.

13. Terlou A, van Seters M, Ewing PC, et al. Treatment of vulvar intraepithelial neoplasia with topical imiquimod: seven years median follow-up of a randomized clinical trial. Gynecol Oncol 2011;121:157-62.

14. Coruh A, Yontar Y. Application of split-thickness dermal grafts in deep partial- and fullthickness burns: a new source of auto-skin grafting. J Burn Care Res 2012;33:e94e100.

15. Rutledge F, Sinclair M. Treatment of intraepithelial carcinoma of the vulva by skin excision and graft. Am J Obstet Gynecol 1968;102:807-18.

16. Caglar H, Delgado G, Hreshchyshyn MM. Partial and total skinning vulvectomy in treatment of carcinoma in situ of the vulva. Obstet Gynecol 1986;68:504-7.

17. Leplege A, Ecosse E, Verdier A, Perneger TV. The French SF-36 Health Survey: translation, cultural adaptation and preliminary psychometric evaluation. J Clin Epidemiol 1998;51:1013-23.

18. Rosen R, Brown C, Heiman J, et al. The Female Sexual Function Index (FSFI): a multidimensional self-report instrument for the assessment of female sexual function. J Sex Marital Ther 2000;26:191-208.

19. Leplege A. Le questionnaire MOS SF-36 - Manuel de l'utilisateur et guide d'interprétation des scores: ESTEM, 2001. 
20. Likes WM, Stegbauer C, Hathaway D, Brown C, Tillmanns T. Use of the female sexual function index in women with vulvar intraepithelial neoplasia. J Sex Marital Ther 2006;32:255-66.

21. Wiegel M, Meston C, Rosen R. The female sexual function index (FSFI): cross-validation and development of clinical cutoff scores. J Sex Marital Ther 2005;31:1-20.

22. Brazier JE, Harper R, Jones NM, et al. Validating the SF-36 health survey questionnaire: new outcome measure for primary care. Bmj 1992;305:160-4.

23. Chafe W, Richards A, Morgan L, Wilkinson E. Unrecognized invasive carcinoma in vulvar intraepithelial neoplasia (VIN). Gynecol Oncol 1988;31:154-65.

24. Modesitt SC, Waters AB, Walton L, Fowler WC, Jr., Van Le L. Vulvar intraepithelial neoplasia III: occult cancer and the impact of margin status on recurrence. Obstet Gynecol 1998;92:962-6.

25. Fanning J, Lambert HC, Hale TM, Morris PC, Schuerch C. Paget's disease of the vulva: prevalence of associated vulvar adenocarcinoma, invasive Paget's disease, and recurrence after surgical excision. Am J Obstet Gynecol 1999;180:24-7.

26. Jones IS, Crandon A, Sanday K. Paget's disease of the vulva: Diagnosis and follow-up key to management; a retrospective study of 50 cases from Queensland. Gynecol Oncol 2011;122:42-4.

27. Wallbillich JJ, Rhodes HE, Milbourne AM, et al. Vulvar intraepithelial neoplasia (VIN 2/3): Comparing clinical outcomes and evaluating risk factors for recurrence. Gynecol Oncol 2012.

28. Parker LP, Parker JR, Bodurka-Bevers D, et al. Paget's disease of the vulva: pathology, pattern of involvement, and prognosis. Gynecol Oncol 2000;77:183-9.

29. Aerts L, Enzlin P, Vergote I, Verhaeghe J, Poppe W, Amant F. Sexual, psychological, and relational functioning in women after surgical treatment for vulvar malignancy: a literature review. J Sex Med 2012;9:361-71.

30. de Melo Ferreira AP, de Figueiredo EM, Lima RA, et al. Quality of life in women with vulvar cancer submitted to surgical treatment: a comparative study. Eur J Obstet Gynecol Reprod Biol 2012;165:91-5.

31. Hazewinkel MH, Laan ET, Sprangers MA, Fons G, Burger MP, Roovers JP. Long-term sexual function in survivors of vulvar cancer: a cross-sectional study. Gynecol Oncol 2012;126:87-92.

32. Basta A. Diagnostic and therapeutic procedures in the vulvar intraepithelial neoplasia (VIN) and early invasive cancer of the vulva. Eur J Gynaecol Oncol 1989;10:55-9.

33. Kenter GG, Welters MJ, Valentijn AR, et al. Vaccination against HPV-16 oncoproteins for vulvar intraepithelial neoplasia. $N$ Engl J Med 2009;361:1838-47.

34. Wang LC, Blanchard A, Judge DE, Lorincz AA, Medenica MM, Busbey S. Successful treatment of recurrent extramammary Paget's disease of the vulva with topical imiquimod 5\% cream. J Am Acad Dermatol 2003;49:769-72.

35. Tonguc E, Gungor T, Var T, Ozat M, Sahin I, Sirvan L. Treatment of recurrent vulvar Paget disease with imiquimod cream: a case report and review of the literature. Arch Gynecol Obstet 2011;283:97-101.

36. Anton C, Luiz AV, Carvalho FM, Baracat EC, Carvalho JP. Clinical treatment of vulvar Paget's disease: a case report. Clinics (Sao Paulo) 2011;66:1109-11.

37. Terlou A, van Seters M, Kleinjan A, et al. Imiquimod-induced clearance of HPV is associated with normalization of immune cell counts in usual type vulvar intraepithelial neoplasia. Int J Cancer 2010;127:2831-40. 
Figure 1: Skinning vulvectomy with split-thickness skin graft surgical procedure

Legends: a. Locating lesions and marking incision lines, b. Skinning vulvectomy, c.

Operative specimen, d. Harvesting the graft, e. Graft, f. Placing the graft, g. Fixing the graft, h. Applying the bolster dressing

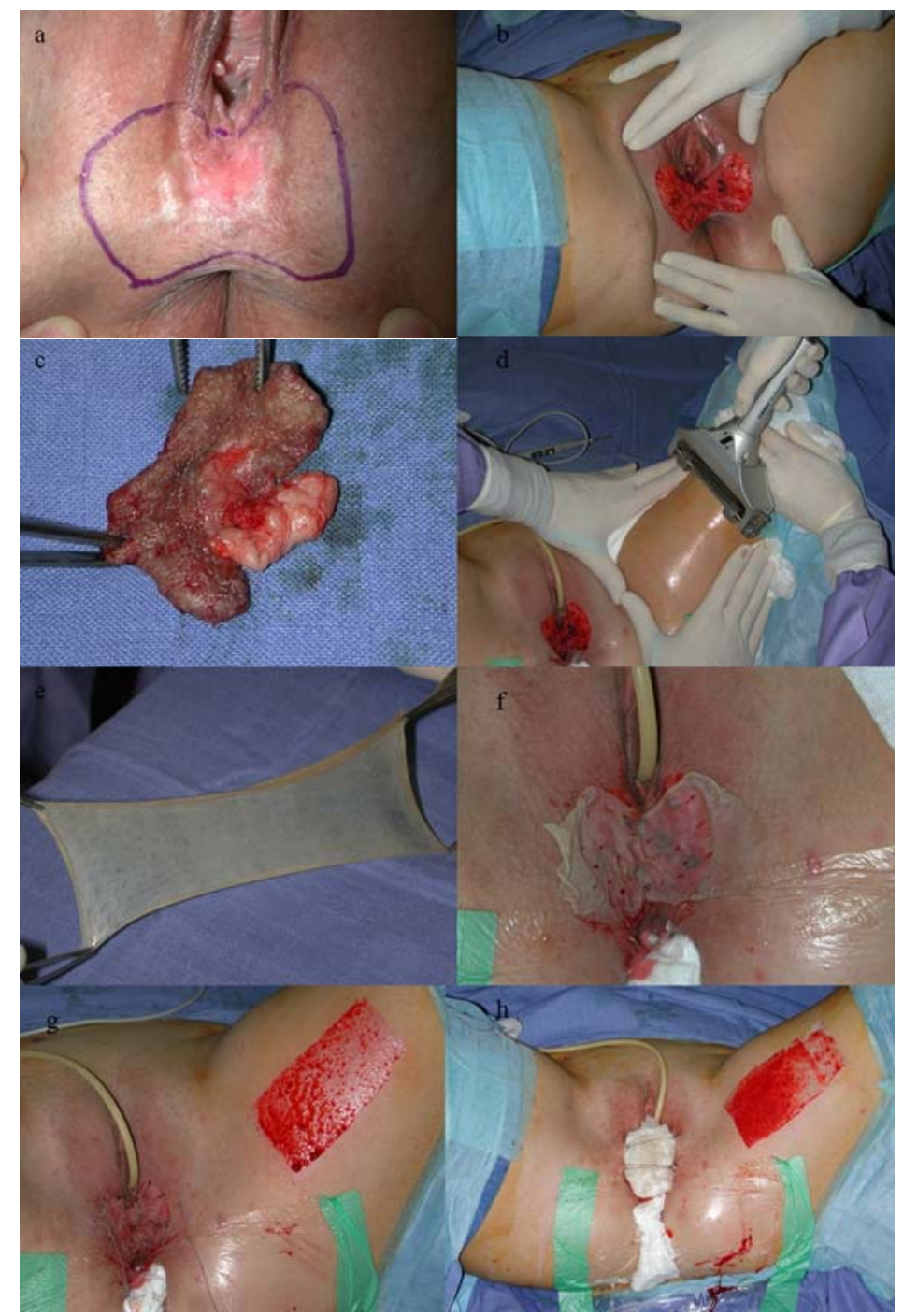


Table 1: Data of 13 patients having undergone skinning vulvectomy with split-thickness skin graft reconstruction.

Pnt: patient; uVIN: Usual-type vulvar intraepithelial neoplasia; dVIN: differentiated-type vulvar intraepithelial neoplasia; K: cancer; DFS: disease-free survival

\begin{tabular}{|c|c|c|c|c|c|c|c|c|c|}
\hline Pnt & $\begin{array}{l}\text { Age } \\
\text { (yrs) }\end{array}$ & $\begin{array}{c}\text { History } \\
\text { of } \\
\text { genital } \\
\text { cancer }\end{array}$ & $\begin{array}{c}\text { Pre } \\
\text { operative } \\
\text { histology }\end{array}$ & $\begin{array}{c}\text { Post } \\
\text { operative } \\
\text { histology }\end{array}$ & Multifocality & Margins & $\begin{array}{l}\text { Adjuvant } \\
\text { treatment }\end{array}$ & Relapse & $\begin{array}{c}\text { D F S } \\
\text { (months) }\end{array}$ \\
\hline 1 & 63 & No & $\overline{\mathrm{uVIN}}$ & $\overline{\mathrm{uVIN}}$ & + & Clear & None & No & 124 \\
\hline 2 & 66 & No & uVIN & uVIN & + & + & None & No & 112 \\
\hline 3 & 33 & No & uVIN & $\mathrm{uVIN}+\mathrm{K}$ & + & Clear & $\begin{array}{c}\text { Unilateral } \\
\text { lymphadenectomy }\end{array}$ & No & 100 \\
\hline 4 & 50 & No & $\mathrm{uVIN}$ & uVIN & + & Clear & None & No & 99 \\
\hline 5 & 69 & Yes & Paget & Paget & + & Clear & None & Yes & 16 \\
\hline 6 & 37 & No & uVIN & uVIN & + & Clear & None & No & 94 \\
\hline 7 & 42 & No & uVIN & uVIN & + & + & None & No & 82 \\
\hline 8 & 34 & No & uVIN & $\mathrm{uVIN}$ & + & + & None & Yes & 10 \\
\hline 9 & 39 & No & uVIN & $\mathrm{uVIN}+\mathrm{K}$ & - & + & Radiotherapy & Yes & 39 \\
\hline 10 & 76 & Yes & $\mathrm{dVIN}$ & $\mathrm{dVIN}$ & + & Clear & None & Yes & 16 \\
\hline 11 & 71 & No & Paget & Paget $+\mathrm{K}$ & + & + & Radiotherapy & No & 48 \\
\hline 12 & 53 & No & $\mathrm{uVIN}$ & uVIN & + & + & None & No & 15 \\
\hline 13 & 62 & No & Paget & Paget $+\mathrm{K}$ & - & + & Radiotherapy & No & 4 \\
\hline
\end{tabular}


Figure 2: Disease Free Survival Curve

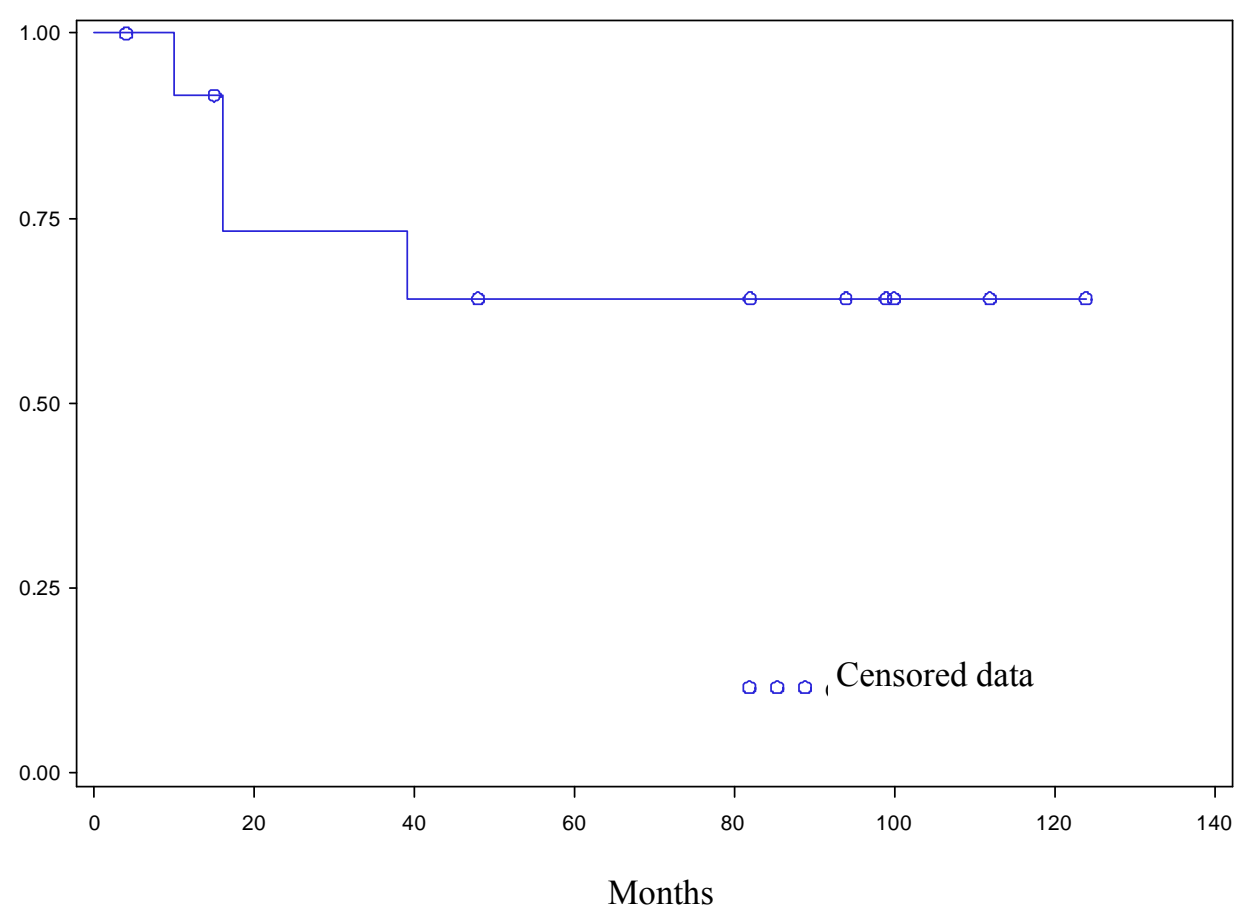


Table 2: Quality of life of patients after skinning vulvectomy with split-thickness skin graft.

\begin{tabular}{llllll}
\hline SF36 domains & \multicolumn{2}{l}{ Reference data } & \multicolumn{2}{l}{ Skinning vulvectomy with } & $\boldsymbol{p}$ \\
& & & \multicolumn{2}{c}{ split-thickness skin graft } & \\
& Mean & SD & Mean & SD & \\
\hline Physical functioning & 84.4 & 21.19 & 74.2 & 26.7 & NS \\
Role-physical & 81.2 & 32.2 & 82.5 & 31.2 & NS \\
Bodily pain & 73.3 & 23.7 & 68.4 & 21.5 & NS \\
General health & 69.1 & 18.5 & 59.1 & 15.4 & NS \\
Vitality & 59.9 & 18.0 & 59.5 & 17.2 & NS \\
Social functioning & 81.5 & 21.4 & 82.5 & 12.0 & NS \\
Role-emotional & 82.1 & 32.1 & 81.4 & 24.2 & NS \\
Mental health & 68.4 & 17.6 & 71.6 & 11.3 & NS \\
\hline
\end{tabular}

NS: Not significant, SD: Standard deviation. 